\title{
Serum IgA antibodies against Pseudomonas aeruginosa in cystic fibrosis
}

\author{
M M Brett, A T M Ghoneim, J M Littlewood
}

\begin{abstract}
Serum IgA antibodies to Pseudomonas aeruginosa cell surface antigens were estimated by ELISA. Titres in patients with and without cystic fibrosis and with no pseudomonal infection were low $(<105$ to $<261)$. Titres in patients with cystic fibrosis who were chronically infected with $\boldsymbol{P}$ aeruginosa were very high (1200-163 000), and patients who grew the organism intermittently had intermediate titres. Longitudinal studies suggested increasing tissue invasion or involvement of the lower respiratory tract, or both, with increasing time of infection and identified patients with a good prognosis after the onset of pseudomonal infection. Detection of an increased serum IgA titre can give an earlier indication than measurement of the serum IgG titre of the presence of $P$ aeruginosa in the respiratory tract in a proportion of patients. IgA measurement seems to be better than IgG measurement at predicting the reappearance of $P$ aeruginosa after apparent eradication of early infection. These results suggest that this Issay may be a valuable additional indicator of the presence of $\boldsymbol{P}$ aeruginosa at the beginning of infection, and of the reappearance of the organism after treatment in the early stages of infection.
\end{abstract}

Despite the widespread use of effective antipseudomonal antibiotics, pulmonary infection with Pseudomonas aeruginosa remains a major cause of morbidity and mortality in patients with cystic fibrosis. ${ }^{1}$ A full understanding of the immunological processes involved in the initial stages of infection of the respiratory tract should assist in successfully combating such infection. The pronounced systemic IgG response to pseudomonal infection has been well documented. ${ }^{2-4}$ Because the bronchial and pulmonary mucosa are the primary sites of infection, IgA antibodies might be expected to have an important role in combating infection, but this is not well understood. The sequence of events in response to infection of a mucosal site should first be production of IgA and secretory IgA (sIgA), which should agglutinate the organisms and so prevent them from growing and from attaching to the host mucosa. When the IgA response is inadequate, IgG antibodies will be produced. ${ }^{5}$ It is possible that patients with cystic fibrosis have a quantative defect in their IgA response that renders them susceptible to infection. In addition, IgA has been reported to be the major humoral immune response in the upper respiratory tract of dogs while IgG predominates in the lower respiratory tract, ${ }^{5}$ so comparison of the IgA and IgG responses may give an indication of the depth of infection. We therefore decided to measure serum IgA antibodies to $P$ aeruginosa in different stages of pulmonary infection, and to compare this with antipseudomonal IgG antibodies in patients' serum.

\section{Patients and methods}

Serum samples were obtained from 139 patients with cystic fibrosis who attended the paediatric and adult clinics at our hospital. $P$ aeruginosa had never been isolated from 33 patients. Their age range was $1-16$ years, mean (SE) 7·3 (1.04). $P$ aeruginosa was isolated on one or more occasions from 57 patients, but they had no recognisable chest illness attributable to that organism. Their ages ranged from 1-26 years, mean $7 \cdot 26(1 \cdot 71)$. Forty nine patients had recognisable chest illness that was attributable to $P$ aeruginosa, which had been isolated continuously for at least six months. Their ages ranged from 10-27 years, mean 15.6 (1·18).

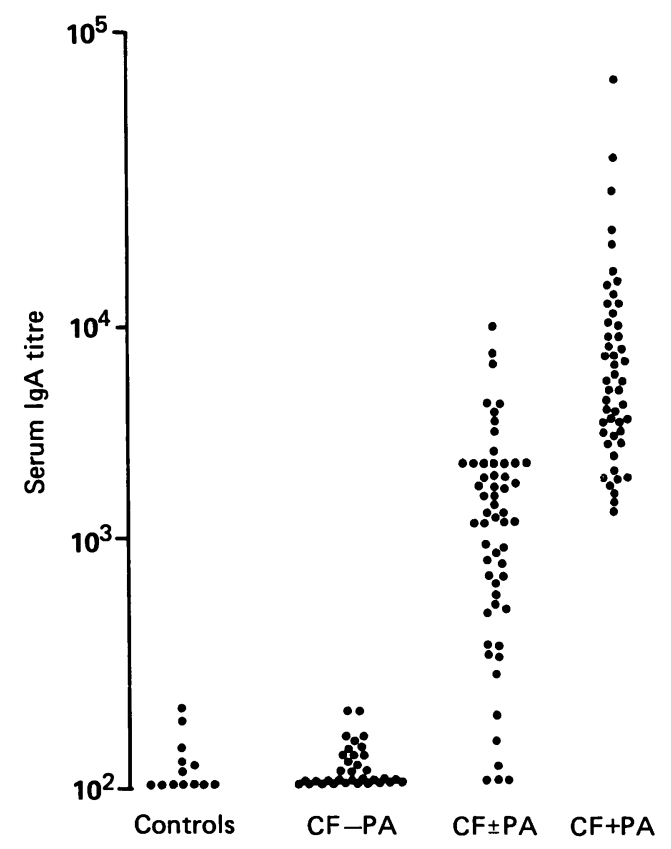

Figure 1 Serum IgA antibody titre to $P$ aeruginosa. IgA antibody titre is the sum of individual titres to $P$ aeruginosa strains with serotypes $1,3,6,9,10,11$, and a strain that could not be serotyped. Controls: paediatric patients with no history of $P$ aeruginosa infection; $C F-P A$ : patients with cystic fibrosis from whom $P$ aeruginosa had never been isolated; $C F \pm P A$ : patients with cystic fibrosis from whom the organism had been isolated at least once; $C F+P A$ : patients with cystic fibrosis from whom $P$ aeruginosa had been isolated continuously for at least six months. 
Overall clinical state was assessed by the Shwachman score. ${ }^{6}$ Declining scores indicate a worsening condition. Films from chest radiography were assessed by the Chrispin-Norman $x$ ray score. ${ }^{7}$ An increasing score indicates increasing abnormality.

The controls comprised 13 patients who attended a paediatric clinic for other reasons. The mean age was $9 \cdot 2(1 \cdot 4)$ years, varying from 8 months to 15 years. None had any evidence of lung disease or $P$ aeruginosa infection.

Serum samples from all the subjects were stored at $-20^{\circ} \mathrm{C}$ until immediately before analysis.

Free serum IgA antibodies to $P$ aeruginosa cell surface antigens were measured by enzyme linked immunoabsorbent assay (ELISA) as previously described. ${ }^{8}$ Seven strains of $P$ aeruginosa with serotypes $1,3,6,9,10,11$, and a strain that could not be serotyped were used. ${ }^{9}$ The serum was diluted $1: 200$ or $1: 2000$

Kendall's rank correlation test ${ }^{10}$ and the Mann-Whitney U test ${ }^{11}$ were used for statistical analysis.

\section{Results}

Free serum IgA titres against $P$ aeruginosa in controls and patients with cystic fibrosis are shown in fig 1 . The titres of 13 control patients ranged from $<105$ to $<261$, mean (SE) 127(13). The titres of 34 patients with cystic fibrosis, from whom $P$ aeruginosa was never isolated during the next three years, ranged from $<105$ to $<216$, mean $127(6 \cdot 0)$.

Forty nine patients with cystic fibrosis who had chronic $P$ aeruginosa all had very high serum IgA titres (between 1200 and 16 300), which were significantly greater than control titres $(\mathrm{p}<0.001)$.

There was a wide range of titres in patients with cystic fibrosis with intermittent $P$ aeruginosa: $51 / 57$ patients had titres that were greater than the control range, between 275 and 6650 . There were two patients in whom IgA titres remained within the control range throughout the study period, despite intermittent isolations of $P$ aeruginosa and increases in IgG titre. No difference in the rate of change of lung function or chest radiography could be detected between these two patients and patients who had increased IgA and IgG titres. Four patients with intermittent $P$ aeruginos $a^{\circ}$ isolations had titres between 105 and 235, which were within the control range. These four patients are considered in more detail in table 1. $P$ aeruginosa was isolated one to three times during a short period from each of these patients. Both IgA and IgG titres were within the control range in serum samples taken at varying times before and after these isolates. Serum IgA and IgG concentrations were also within the normal range throughout the study periods in all four patients.

$P$ aeruginosa was isolated for the first time from 26 patients with cystic fibrosis during the study period. An increase in serum IgA titre, to greater than the control range, was detected up to 24 months before $P$ aeruginosa was first isolated in all 26 patients (fig 2). This appears to be a similar pattern to that previously reported for the IgG titre, ${ }^{12}$ but if the IgA and IgG titres are compared, some differences begin to emerge. The IgA titre increased four to 20 months before an increase in IgG titre was detected in eight patients. This was followed by intermittent $P$ aeruginosa isolations. In contrast, the IgG titre increased nine and 11 months before the $\operatorname{IgA}$ titre increased in two patients. In 16 patients, IgA and IgG titres were both greater than control values in the first available serum sample, one to 24 months before the first isolation of $P$ aeruginosa. In the absence of antipseudomonal intravenous treatment there were further increases in the IgA titre, both before and after the beginning of $P$ aeruginosa isolations. Longitudinal studies of three representative patients are shown in fig 3 .

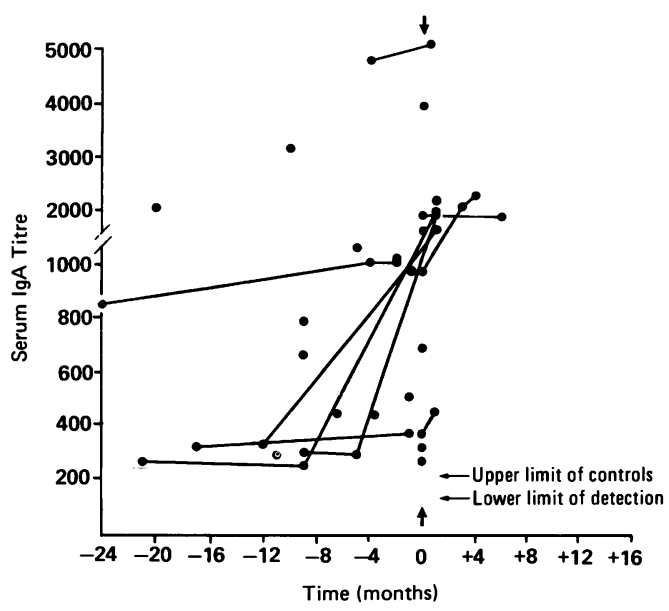

Figure 2 Serum IgA antibody titre to $P$ aeruginosa in 26 patients with cystic fibrosis before and after the first isolation from the respiratory tract. The arrows indicate the time of the beginning of intermittent isolations of $P$ aeruginosa. The upper limit of controls is the statistical limit of $99 \cdot 9 \%$ plus upper limit of controls
$10 \%$ interassay error.

Table 1 Titre of IgA and IgG antibodies to P aeruginosa in patients with cystic fibrosis before and after transient isolation from the respiratory tract

\begin{tabular}{|c|c|c|c|c|c|c|c|c|c|}
\hline \multirow{2}{*}{$\begin{array}{l}\text { Age } \\
\text { (years) }\end{array}$} & \multirow[t]{2}{*}{ Sex } & \multirow{2}{*}{$\begin{array}{l}\text { No of positive } \\
\text { isolations/No } \\
\text { of samples tested }\end{array}$} & \multicolumn{3}{|c|}{ Before isolation } & \multicolumn{3}{|c|}{ After isolation } & \multirow{2}{*}{$\begin{array}{l}\text { Months } \\
\text { without } \\
P \text { aeruginosa }\end{array}$} \\
\hline & & & $\operatorname{Ig} A$ & $\operatorname{Ig} G$ & $\begin{array}{l}\text { Time sample } \\
\text { taken (months) }\end{array}$ & $\operatorname{Ig} A$ & $I g G$ & $\begin{array}{l}\text { Time sample } \\
\text { taken (months) }\end{array}$ & \\
\hline 4 & $\mathbf{F}$ & $1 / 32$ & $<210$ & $\begin{array}{l}<160 \\
<170\end{array}$ & $\begin{array}{c}16 \cdot 5 \\
3\end{array}$ & $\begin{array}{l}<114 \\
<150\end{array}$ & $\begin{array}{l}<190 \\
<150\end{array}$ & $\begin{array}{r}7 \\
17\end{array}$ & 24 \\
\hline 1 & $\mathbf{M}$ & $1 / 26$ & $<105$ & $<140$ & 1 & $\begin{array}{l}<105 \\
<105 \\
<115\end{array}$ & $\begin{array}{l}<140 \\
<140 \\
<140\end{array}$ & $\begin{array}{l}0 \\
6 \\
7\end{array}$ & 23 \\
\hline 6 & $\mathbf{M}$ & $3 / 17$ & $<105$ & $<240$ & $10 \cdot 5$ & $<105$ & $<160$ & 16 & 7 \\
\hline 8 & $M$ & $2 / 16$ & $<180$ & $<140$ & 20 & $<105$ & $<170$ & 3 & 12 \\
\hline
\end{tabular}



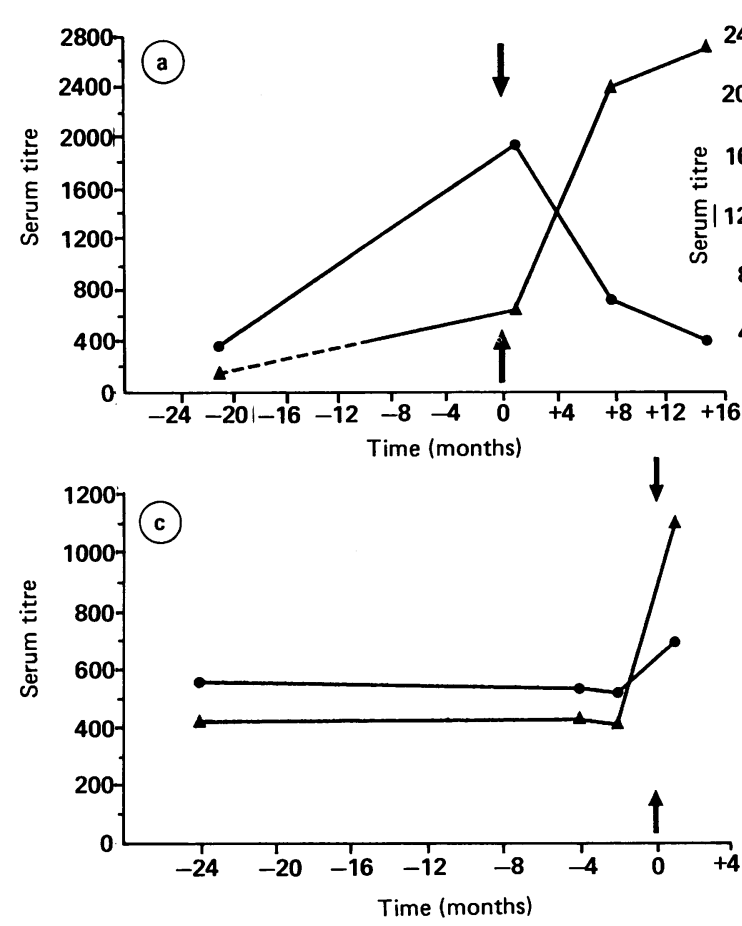

Figure 3 Longitudinal studies of serum IgA and serum IgG antibody titres in three patients with cystic fibrosis before the beginning of intermittent $P$ aeruginosa isolations. Serum IgA titre $-\mathbf{\Delta}-\boldsymbol{\Delta}$ serum IgG titre; dashed lines denote titres within the control range.

A follow up study of six patients from whom the organism was not isolated and the serum IgG titre returned to control concentrations after intravenous treatment showed that in five patients the organism reappeared (five to 37 months after intervenous treatment). In five patients an increase in IgA titre to greater than the control range, followed by further increases in titre, preceded the organism's reappearance (table 2). The IgG titre increased in only one patient before the reappearance of $P$ aeruginosa. It did not increase until after intermittent isolations had begun in the other four patients.

A comparison of $\operatorname{IgA}$ and IgG titres in the different groups of patients is shown in table 3 .
Patients with no known pseudomonal infection had ratios of IgA:IgG titres between 0.35 and 1.65. Patients with intermittent $P$ aeruginosa had a significantly higher ratio than chronically infected patients $(p<0.001)$, although there was a wide range of values in the two groups and some overlap between them. Longitudinal studies of individual patients in both groups showed that in the absence of intravenous treatment, the ratio gradually decreased with increasing time of infection. There was no correlation between the ratio of IgA:IgG titres and Shwachman score or Chrispin-Norman score in the groups of patients who grew $P$ aeruginosa intermittently or chronically.

Table 2 Serum IgA and IgG titres in patients with cystic fibrosis before the recurrence of infection

\begin{tabular}{|c|c|c|c|c|c|c|c|c|}
\hline \multirow{2}{*}{$\begin{array}{l}\text { Case } \\
\text { No }\end{array}$} & \multirow{2}{*}{$\begin{array}{l}\text { Age (years) } \\
\text { and sex }\end{array}$} & \multicolumn{3}{|c|}{ Before treatment ${ }^{*}$} & \multicolumn{4}{|c|}{ After treatment } \\
\hline & & $\begin{array}{l}\text { Time sample } \\
\text { taken } \\
\text { (months) }\end{array}$ & $I g A$ & $\operatorname{Ig} G$ & $\begin{array}{l}\text { Time sample } \\
\text { taken } \\
\text { (months) }\end{array}$ & $I g A$ & $I g G$ & $\begin{array}{l}P \text { aeruginosa } \\
\text { reisolated } \\
\text { (months)t }\end{array}$ \\
\hline 1 & $5 \mathrm{~F}$ & 9.5 & 790 & 485 & $\begin{array}{r}0 \\
22 \\
26\end{array}$ & $\begin{array}{c}(220) \\
250 \\
1630\end{array}$ & $\begin{array}{l}(140) \\
(140) \\
(150)\end{array}$ & $>31$ \\
\hline 2 & $15 M$ & 1 & 370 & 340 & $\begin{array}{r}0 \\
22 \\
29\end{array}$ & $\begin{array}{l}320 \\
370 \\
370\end{array}$ & $\begin{array}{l}(190) \\
(140) \\
(140)\end{array}$ & 33 \\
\hline 3 & $4 \mathrm{~F}$ & 15 & ND & 475 & $\begin{array}{l}11 \\
15 \\
23 \\
37 \\
42\end{array}$ & $\begin{array}{r}290 \\
300 \\
350 \\
580 \\
\mathrm{ND}\end{array}$ & $\begin{array}{c}(190) \\
(144) \\
(230) \\
(170) \\
690\end{array}$ & 37 \\
\hline 4 & $11 \mathrm{~F}$ & 19.5 & 240 & 450 & $\begin{array}{r}0 \\
9 \\
26\end{array}$ & $\begin{array}{r}1250 \\
1540 \\
\mathrm{ND}\end{array}$ & $\begin{array}{l}(170) \\
375 \\
420\end{array}$ & 23 \\
\hline 5 & $23 \mathrm{~F}$ & 0 & 320 & 430 & $\begin{array}{l}0 \\
4 \\
9\end{array}$ & $\begin{array}{l}410 \\
460 \\
490\end{array}$ & $\begin{array}{l}(230) \\
(270) \\
535\end{array}$ & 5 \\
\hline 6 & $25 \mathrm{~F}$ & 2 & 1100 & 580 & $\begin{array}{l}13 \\
23 \\
26 \\
31 \cdot 5\end{array}$ & $\begin{array}{r}690 \\
1100 \\
2600 \\
10000\end{array}$ & $\begin{array}{c}(214) \\
390 \\
590 \\
4700\end{array}$ & 14 \\
\hline
\end{tabular}

Figures in parentheses indicate titres within the control ranges. ND=not done.

*Treatment was two weeks of an intravenous aminoglycoside (for example, tobramycin, amikacin) and a ureidopenicilin (for example, azlocillin, piperacillin).

†The time after treatment when $P$ aeruginosa was reisolated from the patient. 
Table 3 Ratio of serum IgA titre to serum IgG titre in patients with cystic fibrosis

\begin{tabular}{|c|c|c|c|c|c|c|}
\hline & \multicolumn{2}{|l|}{$I g A: I g G$} & \multirow{2}{*}{$\begin{array}{l}\text { Shwachman } \\
\text { score }\end{array}$} & \multirow{2}{*}{$\begin{array}{l}\text { Chrispin- } \\
\text { Norman score }\end{array}$} & \multirow[t]{2}{*}{ IgA titre } & \multirow[t]{2}{*}{$\operatorname{IgG}$ titre } \\
\hline & Mean $(2 S D)$ & Range & & & & \\
\hline $\begin{array}{l}P \text { aeruginosa not present }(\mathrm{n}=33) \\
\text { Intermittent } P \text { aeruginosa }(\mathrm{n}=38) \\
\mathrm{n}=1(\mathrm{a}) \\
\text { Chronic } P \text { aeruginosa }(\mathrm{n}=35) \\
\mathrm{n}=1(\mathrm{~b})\end{array}$ & $\begin{array}{l}0 \cdot 72(0 \cdot 53) \\
2 \cdot 2(0 \cdot 19) \\
6 \cdot 0,9 \cdot 7^{*} \\
1 \cdot 05(0 \cdot 15) \\
9 \cdot 7,14 \cdot 2^{*}\end{array}$ & $\begin{array}{l}0.35-1.65 \\
0.69-5.05\end{array}$ & $\begin{array}{l}75-100 \\
65-90 \\
100 \\
45-85 \\
95\end{array}$ & $\begin{array}{l}0-6 \\
2-11 \\
2 \\
9-24 \\
3\end{array}$ & $\begin{array}{c}<105-<200 \\
176-2800 \\
3500,6640 \\
1200-16300 \\
1600,1980\end{array}$ & $\begin{array}{l}<140-<240 \\
306-1050 \\
370,950 \\
1200-20500 \\
<140,<166\end{array}$ \\
\hline
\end{tabular}

${ }^{*}$ Denotes significance of $p<0 \cdot 001$. Each patient is represented by one value except (a) was seven readings two years apart and (b) was two readings three years apart.

There were, however, two patients (one with intermittent and one with more than five years of chronic $P$ aeruginosa) who stood out as being different. They both had a significantly higher ratio of IgA:IgG titres than the other patients in the corresponding group $(p<0.001)$, which was maintained over a period of several years. This was due to a very pronounced $\operatorname{IgA}$ response and a very low IgG response. Both patients had much higher Shwachman scores and lower Chrispin-Norman scores than the other patients in the same group.

\section{Discussion}

All patients with cystic fibrosis with chronic pseudomonal infection had a very pronounced IgA response. Patients with intermittent $P$ aeruginosa also had titres greater than the control range, with the exception of six patients. Two of these six patients had no detectable increase in serum IgA titre throughout periods of 12-22 months of repeated $P$ aeruginos $a$ isolations and increased IgG titres, which are indicative of infection. ${ }^{12} 13$ There was no difference in clinical variables between these two patients and patients who had increased IgA titres. Consistent changes in clinical variables, however, are detectable only in patients with chronic pseudomonal infection, ${ }^{2}$ so these two patients may need to be studied for a longer time before any conclusions can be drawn on the effect of a lack of specific serum IgA antibodies on their prognosis. Furthermore, a lack of IgA antibodies in serum should be interpreted with caution in the absence of data on concentrations in sputum: a dissociation between local and systemic concentrations of precipitins against $P$ aeruginosa and Staphylococcus aureus has been reported for some antigens in a small number of patients with chronic infection. ${ }^{14}$

In contrast, four patients had no detectable increase in both IgA and IgG titres during periods of up to 17 months before and after one to three isolations of $P$ aeruginosa. Serum concentrations of IgA and IgG remained within the normal range throughout the study period. It is unlikely that antibodies to $P$ aeruginosa were present in serum but not detected: the outer membrane proteins of $P$ aeruginosa are highly conserved, ${ }^{15}$ and the serotypes of isolates from these patients were included in the assay. The absence of a systemic IgG response implies the absence of tissue invasion and infection, ${ }^{1213}$ and the lack of a detectable systemic IgA response suggests that either local pulmonary antibody synthesis was adequate or that isolates were transient and not present in either suffi- cient numbers or for sufficient time to induce systemic IgA. It should be emphasised that this was not a common finding: the vast majority of our patients from whom $P$ aeruginosa was isolated are infected.

Among all patients with an IgA titre greater than the control range there was no correlation between $\operatorname{IgA}$ titre and the Chrispin-Norman chest $x$ ray score, even in patients with chronic pseudomonal infection, where pulmonary changes are more pronounced and predominantly caused by $P$ aeruginosa. IgA production is an initial immune response to the presence of an infective agent in the pulmonary cavity, and one of its main functions is to prevent adhesion of organisms to pulmonary mucosa. ${ }^{5}$ IgA production is, therefore, unlikely to bear any relation to the amount of tissue fibrosis and endobronchial inflammation which contribute to the chest $x$ ray score. Indeed, increased IgA production could occur with no detectable change in the chest radiograph if it prevents bacterial adherence to pulmonary mucosa and hence tissue damage. If the IgA response is not sufficient to prevent bacterial growth and adhesion then IgG production is induced, which we have shown to correlate with changes in chest $x$ ray score. ${ }^{2}$

The results presented here show that the vast majority $(90 \%)$ of patients with cystic fibrosis produce specific IgA antibodies before the organism is present in sufficient numbers to be isolated from the respiratory tract $\left(10^{4}-10^{5}\right.$ colony forming units $/ \mathrm{ml}$ in our laboratory) but this does not prevent pseudomonal infection becoming established and eventually overwhelming. It is possible that although the serum titre is increased, the sputum concentration is not increased or is insufficient to cope with the bacterial load. A defect in the assembly of sIgA has been reported, ${ }^{16}$ which would render it more susceptible to cleavage by proteases produced by $P$ aeruginosa. Another possibility is that, although the $\operatorname{IgA}$ concentration in the lungs is adequate, there are defects in nonspecific components, such as ciliary movement or phagocytosis, so that removal of organisms from the respiratory tract could be suboptimal.

The presence of serum IgA antibodies, which have been shown to be specific for $P$ aeruginosa ${ }^{8}$ at higher concentrations than normal would seem to indicate the presence of the organisms in the respiratory tract. It could be argued that increased serum $\operatorname{IgA}$ antibodies in the absence of serum IgG antibodies signifies harmless colonisation, rather than tissue invasion and infection. What is perhaps of greatest importance to the patient is treatment at a stage 
when the course of infection can be radically altered.

We have shown previously that treatment at an early stage of infection apparently eradicated pseudomonal infection (as judged by bacteriology and serum IgG titres) in six of 16 patients. ${ }^{12}$ After intervals of five to 32 months, $P$ aeruginosa again began to be isolated from five of these six patients. It appears that IgA measurement may be better than IgG measurement at predicting the recurrence of pseudomonal infection: an increase in IgA titres was detected in all five patients before the organism reappeared, whereas an increase in IgG titre was only detected in one patient. This was an unexpected finding; the cause and its significance are unclear, but should be clarified.

Because both IgA and IgG are involved in the immune response to $P$ aeruginos $a$ we considered the association between them. The ratio of IgA:IgG titres decreased in individual patients with increasing time of infection, so patients with intermittent $P$ aeruginosa had a significantly higher ratio of IgA:IgG titres than patients with chronic $P$ aeruginosa. There was some overlap between the two groups, presumably due to the arbitrary division between them. There were two patients (one with intermittent and one with chronic $P$ aeruginosa) who stood out as being totally anomalous. They both had ratios that were significantly higher than other patients in the same group, maintained over study periods of two to three years. These two patients both showed a lack of clinical deterioration: their clinical state and chest radiograph were dramatically better than those of the other patients in the corresponding group. Both these patients had a very pronounced $\mathrm{IgA}$ response and an IgG response that was very low or absent. A high ratio of $\operatorname{IgA}: \operatorname{IgG}$ could be caused in two ways, both of which suggest a less damaging infection. A high ratio could be indicative of an IgA response which is sufficient to prevent tissue invasion and so there is no stimulus to induce IgG production. Alternatively, it is possible that, as IgA antibodies predominate in the upper airways while IgG antibodies predominate in the lower respiratory tract, ${ }^{5}$ a high ratio could indicate an infection predominantly in the upper airways while a low ratio suggests infection deeper in the lungs.

In conclusion, the serum IgA response to $P$ aeruginosa seems to follow a similar pattern to that of serum IgG antibodies: titres were very low in patients with no history of pseudomonal infection, high in patients with intermittent
$P$ aeruginosa, and very high in patients with chronic $P$ aeruginosa. Measurement of IgA titres has confirmed that $P$ aeruginosa isolates were transient and non-pathogenic in a small proportion of patients. Comparison of the $\operatorname{IgA}$ and IgG titres identifies those patients with a very good prognosis after the onset of pseudomonal infection. These results suggest that $\operatorname{IgA}$ measurement could improve still further patient management in two situations. First, by predicting the reappearance of $P$ aeruginosa after apparent eradication and secondly, in some patients, by giving an even earlier indication than IgG measurement of the presence of the organism in the respiratory tract in the very earliest stages of infection.

This work was supported by a grant from the Cystic Fibrosis Research Trust.

1 Mearns MB, Hunt GH, Rushworth R. Bacterial flora of respiratory tract in patients with cystic fibrosis, 1950-1971. Arch Dis Child 1972;47:902-7.

2 Brett MM, Ghoneim ATM, Littlewood JM. Serum antibodies to Pseudomonas aeruginosa in cystic fibrosis. Arch Dis Child 1986;61:1114-20.

3 Brett MM, Ghoneim ATM, Littlewood JM. Serum IgG antibodies in patients with cystic fibrosis with early Pseudobodies in patients with cystic fibrosis with early Pseudo-
monas aeruginosa infection. Arch Dis Child 1987;62: monas

4 Pederson SS, Espersen F, Hoiby N. Diagnosis of chronic Pseudomonas aeruginosa in cystic fibrosis by enzymelinked immunosorbent assay. $\mathcal{F}$ Clin Microbiol 1987;25 $1830-6$.

5 Kaltreider HB. Expression of immune mechanisms in the lung. Amer Rev Respir Dis 1976;113:347-79.

6 Shwachman H, Kulczycki LK. Long term study of one hun dred and five patients with cystic fibrosis. Am $\mathcal{F}$ Dis Child 1958;96:6-15.

7 Chrispin AR, Norman AP. The systemic evaluation of the chest radiograph in cystic fibrosis. Pediatr Radiol 1974;2:101-6.

8 Brett MM, Ghoneim ATM, Littlewood JM. An ELISA to detect antipseudomonal IgA antibodies in sera of patients with cystic fibrosis. I Clin Pathol 1988;41:1130-4.

9 Liu PV, Matsumoto H, Kusama H, Bergan T. Survey of heat-stable, major somatic antigens of Pseudomonas aeruginosa. International foumal of Systematic Bacteriology 1983;33:256-64

10 Swinscow TDV. Rank correlation. Statistics at square one. 8th Ed. London: British Medical Association, 1983:71-6. 11 Lentner C, ed. Geigy scientific tables. 8th Ed. Vol 2. Basle: Ciba Geigy, 1982:228

12 Brett MM, Ghoneim ATM, Littlewood JM. Prediction and diagnosis of early Pseudomonas aeruginosa infection in cystic fibrosis in a follow up study. F Clin Microbio 1988;26:1565-70.

13 Hoiby N. Pseudomonas aeruginosa infection in cystic fibrosis. Acta Pathol Microbiol Immunol Scand [Suppl] Section C 1977;263:1-95.

14 Schoitz PO, Hoiby N, Permin H, Wiik A. IgA and IgG antibodies against surface antigens of Pseudomonas aeruginosa in sputum and serum from patients with cystic fibrosis. Acta Pathol Microbiol Immunol Scand Section C 1979;87: 229-33.

15 Hancock REW, Wieczorek AW, Mutharia LM, Poole K. Monoclonal antibodies against Pseudomonas aeruginosa outer membrane antigens: isolation and characterisation. outer membrane antigens: iso

16 Wallwork JC, Brenchley P, McCarthy J, et al. Some aspects of immunity in patients with CF. Clin Exp Immuno 1974;18:303-20. 